\title{
Characterisation of Hydrological Drought and Implications for Sustainable Water Resources Management in the Sokoto-Rima River Basin (SRRB), Nigeria
}

\author{
Martins Yusuf Otache1, Onemayin David Jimoh², John Jiya Musa1, Abdullahi Danmagaji ${ }^{3}$ \\ ${ }^{1}$ Department of Agricultural \& Bioresources Engineering, Federal University of Technology, Minna, Nigeria \\ ${ }^{2}$ Department of Civil Engineering, Federal University of Technology, Minna, Nigeria \\ ${ }^{3}$ Sokoto-Rima River Basin Development Authority, Sokoto, Nigeria \\ Email: martynso_pm@futminna.edu.ng,drotachemartyns@gmail.com
}

How to cite this paper: Otache, M.Y., Jimoh O.D., Musa, J.J. and Danmagaji, A. (2020) Characterisation of Hydrological Drought and Implications for Sustainable Water Resources Management in the Sokoto-Rima River Basin (SRRB), Nigeria. Open Journal of Modern Hydrology, 10, 65-79.

https://doi.org/10.4236/ojmh.2020.103005

Received: April 28, 2020

Accepted: June 16, 2020

Published: June 19, 2020

Copyright $\odot 2020$ by author(s) and Scientific Research Publishing Inc. This work is licensed under the Creative Commons Attribution International License (CC BY 4.0).

http://creativecommons.org/licenses/by/4.0/

(c) $\underset{\mathrm{By}}{\text { (i) Open Access }}$

\begin{abstract}
Hydrological drought is usually characterised by water loss over time from both underground and surface supplies. Thus for this study, the assessment of hydrological drought was carried out by employing Cumulative Rainfall/Streamflow Anomaly as preliminary tools for the presence of drought signatures while detailed characterisation was via Streamflow Drought Index (SDI). The results revealed that hydrological drought was observed in all the stations; however, though in general, the stations could be classified as experiencing near normal drought conditions with mild drought signatures. The findings also revealed that the average streamflow deficit volume and durations of the hydrological drought severity were $1.780 \mathrm{Mm}^{3}$ and 192 months, $1.444 \mathrm{Mm}^{3}$ and 252 months, $3.148 \mathrm{Mm}^{3}$ and 252 months, and $0.159 \mathrm{Mm}^{3}$ and 372 months for Bakolori, Goronyo (pre dam construction era), Goronyo (post dam construction era) and Zobe stations, respectively. The results also revealed the relevance of flow duration curve and analysis of frequency of drought state transition for the development of scenario-based basin water resources management protocol. The coefficient of determination $\left(\mathrm{R}^{2}\right)$ statistic of the developed regression models indicate that $73.3 \%$ and $86.5 \%$ variation in streamflow dynamics across the Basin can be explained by climate change variables. However, for sustainable management of water resources in the Basin, it is imperative that characterisation of hydrological drought and monitoring should employ robust indices which use improved monthly precipitation estimates under global warming scenario in addition to ensuring that there is a shift from reactive to proactive approach in order to combat
\end{abstract}


hydrological risk. Hence, a robust framework that finds application both for planning mitigation actions which embody strategic, tactical and emergency components should be designed; to this end, analysis of persistence and recurrence of drought in time and determination of possible recurrent patterns are necessary.

\section{Keywords}

Hydrological Drought, Water Resources, Sustainability, Management, Climate Change

\section{Introduction}

Drought is a stochastic natural phenomenon that has great impacts on the economy, society and environment of any nation. Thus its determination, monitoring and characterisation are of great significance in water resources planning and management. It is a complex natural hazard which is a composition of many factors such as hydrological, meteorological and agricultural; all are highly influenced by lack of precipitation amount and its frequency. But as reported by Ali et al. [1], hydrological drought occurs when dry weather patterns outweigh other climatic conditions. This calls for routine assessment of water resource availability to meet demands coupled with evaluations of water shortage risk through the analysis of different elements of the water supply system. Hydrological drought is determined accordingly by Van Loon and Laaha [2] in terms of the propagation of meteorological drought through the terrestrial hydrological cycle. This means that it is the significant decrease in the availability of water in all forms appearing in the land phase of the hydrological cycle [3]; by extension, a hydrological drought episode is related to stream flow deficit with respect to normal condition [3]. Since the definition of drought is dependent on the objective of a particular study, which is perhaps important in an attempt to quantify drought, it then becomes imperative to look at hydrological drought as a broad term related to negative anomalies in surface and sub-surface water. But if hydrological drought is framed as a natural hazard, terms for the hazard literature such as vulnerability and resilience are employed. On the other hand, hydrological drought can be seen as a water resources issue which focuses more on the imbalance between water availability and demand [4].

According to Mishra and Singh [5], Pozzi et al. [6], hydrological drought deserves more attention due to its crucial link with drought impacts. In many cases, hydrological drought period leads to shortfall in hydro-power generation. In Nigeria, shortfall of power generation from Kainji dam due to drought has led to power rationing with many cities in black out. Similarly, according to IPCC report as in Sceneviratne et al. [7], there is need to pay more attention to the space-time development of hydrological drought. Against this backdrop there- 
fore, this study is primarily designed to determine the presence or otherwise of hydrological drought in the Sokoto Rima Basin, Nigeria and hence characterise same.

\section{Study Location and Hydrometeorology}

The Sokoto-Rima Basin is located within Latitude $10^{\circ} \mathrm{N}$ and $14^{\circ} \mathrm{N}$ and Longitude $4^{\circ} \mathrm{E}$ and $9^{\circ} 5^{\prime} \mathrm{E}$, respectively. The entire Basin is classified as belonging to Hydrological Area One (HA.1) according to Nigerian Hydrological Service Agency (NIHSA). It belongs to the semi-arid region of the country with pre-dominant Sudan vegetation. The average annual rainfall is between $364-970 \mathrm{~mm}$. The River Basin is majorly serviced by four dams (i.e. Goronyo, Bakolori, Zobe, and Jibia); largely for water supply, irrigation and domestic use by the riparian communities. Figure 1 shows the gauging stations that were considered for the study; this includes the network of the stations and the dam sites.

For the study, data sets on precipitation, (in this case, rainfall), evaporation and streamflow for the Sokoto-Rima Basin were obtained for Sokoto, Goronyo, Gusau, Bakolori, Katsina, Zobe, Jibia gauging stations. Time sequences ranging from 16 years (1963-1978) to 105 years (1910-2015) on these hydrometeorological phenomena were deployed for the study; they were obtained from Nigerian Meteorological Office: NIMET and Sokoto-Rima River Basin Development Authority (SRRBDA) Zonal offices across the four States (Katsina, Zamfara, Sokoto and Kebbi). These data sequences were of monthly temporal resolution.

\section{Methodology}

\subsection{Determination of Drought Threshold}

To properly appreciate the spatial and temporal pattern of the drought regime, the Variable Threshold Method was employed; that is, because of seasonality implication, seasonally varying truncation levels against the traditional constant threshold approach was adopted. This approach was adopted against the backdrop of the fact that it does not require a prior knowledge of probability distribution; by extension, this method directly produces drought characteristics (e.g. frequency, duration, and severity).

According to the Threshold Level Method (TLM), a drought is observed once the variable of interest $X$ (e.g. Streamflow) is equal to or drops below a pre-defined threshold. For this study, this threshold was defined from the streamflow percentile statistics. Based on the recommendation of Huijgevoort et al. [8], the 20th percentile, also known as the 80th exceedance percentile was adopted. To do this, the entire streamflow series of monthly series was arranged in ascending order; that is, from the smallest to the largest. The monthly data points were converted into their respective percentiles: $\bar{X}_{P, T}$, where $T=1,2, \cdots, 12$ or simply $P T$. The percentile $\left(P_{i}\right)$ of the data set was computed according to Robertson (2004) as reported in Danmagaji [9]; Equation (1) details the numerical framework. 


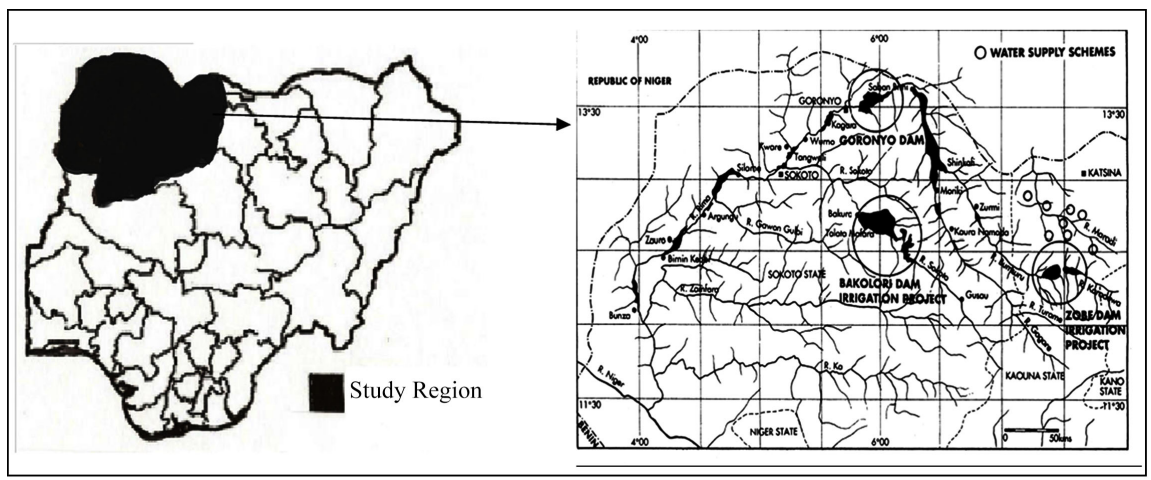

Figure 1. Sokoto Rima River Basin showing Dams and Gauging Stations. Source: Danmagaji [9].

$$
P_{i}=100\left(\frac{i-0.5}{n}\right)
$$

where $n=$ total number of observation, $x_{i}=$ the pith percentage of the data set. Due to the possibility of seasonal variability in the streamflow series, thresholds were defined for each month; i.e. $P_{20}, T, T=1,2,3, \cdots, 12$. For this scheme, a drought was assumed to occur if the calculated percentile value is equal to or smaller than the defined threshold (i.e. $P T \leq$ Thresholds, T).

\subsection{Hydrological Drought Characterisation}

In line with the thoughts of Nalbantis [3], various hydrological variables are used to describe the availability of water in all its forms in the land phase of the hydrological cycle but the most significant variable from the view point of quantity of water is streamflow. This connotes that a hydrological drought episode is related to streamflow deficit with respect to normal conditions. This forms the basis for the employment of the Streamflow Drought Index (SDI) for the hydrological drought analysis in real-time. Sequel to the proceeding section, exclusive use of streamflow was adopted here. Towards this end, as in the classical approach in treating time, successive non-overlapping time intervals were used. In this study, time was treated as follows: April, the first was considered the beginning of the hydrological (water year); every three months, a drought assessment was made regarding the time interval from the start of the hydrological year up to that time of reckoning; thus, time intervals of duration of three, six, nine and twelve months were used. Based on the time series of Streamflow volumes $\left(Q_{i j}\right)$ where $i$ denotes the hydrological year and $j$ the month within the hydrological year ( $j=1$ for April and $j=12$ for March). That is,

$$
V_{i, k}=\sum_{j=1}^{3 k} Q_{i, j}, i=1,2, \cdots ; j=1,2, \cdots, 12 ; k=1,2,3,4
$$

where $V_{i, k}$ is the cumulative Streamflow volume for the $i$-th hydrological year and the $k$-th reference period. Using the cumulative streamflow volumes $\left(V_{i, k}\right)$ as the platform, the Streamflow Drought Index (SDI) was defined for each reference period $k$ of the $i$-th hydrological year as 


$$
S D I_{i, k}=\frac{V_{i, k}-\overline{V_{k}}}{S_{k}}, i=1,2, \cdots ; k=1,2,3,4
$$

where $\overline{V_{k}}$ and $S_{k}$ are respectively the mean and the standard deviation of cumulative Streamflow volume of reference period $k$, these were estimated over a long period of time. This means that the truncation level was set to $\overline{V_{k}}$. As reported in Nalbantis [3], Streamflow may follow a skewed probability distribution, thus a two parameter log-normal distribution in a simple normalisation exercise was done; in this case, natural logarithms of the streamflow for the stations were taken accordingly. This was implemented according as

$$
S D I_{i, k}=\frac{y_{i, k}-\overline{y_{k}}}{S_{y, k}}, i=1,2, \cdots ; k=1,2,3,4
$$

where

$$
y_{i, k}=\ln \left(V_{i, k}\right), \quad i=1,2, \cdots ; k=1,2,3,4
$$

are the natural logarithms of cumulative streamflow with mean $\overline{Y_{k}}$ and standard deviation, $S_{y i k}$.

\subsection{Frequency of State Transition}

Based on the historical streamflow series, SDI was computed; this yields a series of drought states. The series $S D I_{i, k}$ of the SDI index was then calculated by employing Equation (4) and from this, the series of states $X_{i, k}(i=1,2, \cdots, N ; k=1,2,3,4)$ was obtained according to the criteria of Table 1 . In doing this, for each $k$, the related State process $X_{i, k}$ takes discrete values $m \in(0,1,2,3,4)$. The frequency of appearance of each state $\mathrm{m}$ in each reference period $k, f_{m, k}$ was estimated as

$$
f_{m, k}=\frac{n_{m, k}}{N}
$$

where $n_{m, k}$ is the number of occurrences of state $\mathrm{m}$ in reference period $k$ within the available sample of $N$ year.

Using the features vectors of Table 1, the frequency of state transition $F_{m, m^{\prime}, k}$ from state in reference period $k$ to state $\mathrm{m}$ in reference period $k+1$ was computed as in Equation (7)

Table 1. Definition of state of hydrological drought.

\begin{tabular}{cccc}
\hline State & Description & Criterion & Probability (\%) \\
\hline 0 & Non-drought & SDI $\geq 0.0$ & 50.0 \\
1 & Mild drought & $-1.0 \leq \mathrm{SDI}<0.0$ & 34.1 \\
2 & Moderate drought & $-1.5 \leq \mathrm{SDI}<-1.0$ & 9.2 \\
3 & Severe drought & $-2.0 \leq \mathrm{SDI}<-1.5$ & 4.4 \\
4 & Extremely drought & SDI $<-2.0$ & 2.3 \\
\hline
\end{tabular}

Source: Nalbantis [3], Sardou and Bahremand [10]. 


$$
F_{m, m^{\prime}, k}=\frac{n_{m, m^{\prime}, k}}{\sum_{m^{\prime}} n_{m, m^{\prime}, k}}
$$

Based on Table 1, the frequency values of different drought conditions were determined. Thus for each state, the deviations of the periods from the seasonal thresholds were tallied and expressed respectively as a percent of the total number of the drought occurrences.

\subsection{Development of Flow Duration Curves and Regression Models}

To account for the variability in the nature of the flow trend regime for the stations, Flow Durations Curves (FDC) were established based on monthly data series of the Streamflow. In this case, monthly FDCs were established for Zobe dam, Jibia, Bakolori, Goronyo (i.e. pre and post dam situations). In addition to the FDCs, to be able to properly understand the flow characteristics for effective management of the reservoirs considering demand and supply regime, appropriate regression models were developed. The regression models were established based on the sole objective of simulating the upper bound of the established FDCs in terms of percentage exceedance levels.

\subsection{Rainfall/Streamflow Anomaly Analysis}

In view of the fact that the rainfall anomaly directly measures the shortage of rainfall, and is basically quantified as the difference between the observation and the long-term climatological mean, both discrete and cumulative anomalies on annual and seasonal/periodic basis were done for both rainfall and streamflow. Since the discrete anomaly approach is typically primitive, the cumulative anomaly was thus employed along to complement the short comings of the former. In specific terms, the deviations of the periods or monthly measurements from long-term monthly average were tallied. But since the relative importance of the cumulative precipitation anomaly depends largely upon the magnitude of the anomaly in relation to normal conditions [11], to account for this effect, Foley (1957) approach as reported in Keyantash and Dracup [11] was adopted. This requires that each anomaly was normalised with the cumulative anomaly being expressed in thousandths of the annual rainfall or streamflow.

\section{Discussion}

\section{Hydrological Characterisation and Frequency of State Transition}

As expressed by Nalbantis [3], each drought event is characterised through four attributes: 1) its severity expressed by a drought index, 2) its time of onset and duration, 3) its areal extent, and 4) its frequency of occurrence, the most significant variable from the view point of quantity of water is the streamflow. Hence, a hydrological drought episode is related to streamflow deficit with respect to normal conditions. In the application of the SDI approach, a set of seasonally varying values of the truncation level was adopted; in this case, the periodic means. 
Table 2 presents the computed values of the SDI for each station. From the results, it is obvious that non-drought conditions dominate with minor traces of mild drought events. Based on probability of each state condition, using the SDI approach as an exclusive methodology for assessing the hydrological drought condition may not really augur well as seen here. It is glaring that the entire basin exhibits non-drought conditions as evidenced by the results using the exemplar stations even though extensive periods of drought are noticeable in some stations.

Figure 2 and Table 2, Table 3 show the frequency values of different drought conditions and the state transitions for the respective stations. It is imperative to note that in order to really appreciate the true state of hydrological drought incidences, longer accumulation reference periods were considered as noted in Table 2, Table 3. The results showed clearly that the occurrence probability of non-drought in all the stations is staggeringly higher relatively. However, traces of mild drought are discernible (Figure 2 and Table 2, Table 3 ). This is more so considering the fact that in the overall, the state transition frequency does not show significant dispersions.

Within this general context, it suffices to submit that arbitrary classification of drought states as espoused by the SDI methodology creates problems as the nature of a particular flow regime could be intermittent, ephemeral and perhaps perennial. This becomes critical especially as noted in the findings of Nalbantis [3], some drought states according to the definitions of SDI could become irrelevant since cumulative streamflow will always definitely have positive value. Despite this though, as noted, the matrix of frequency of state transition allows for robust predictive capacity of drought. Against this backdrop therefore, since hydrological data length and its associated integrity are vital elements, cognisance should be taken to ensure that monitoring of drought should be accomplished based on priorities of sensitive areas rather than simple drought occurrences.

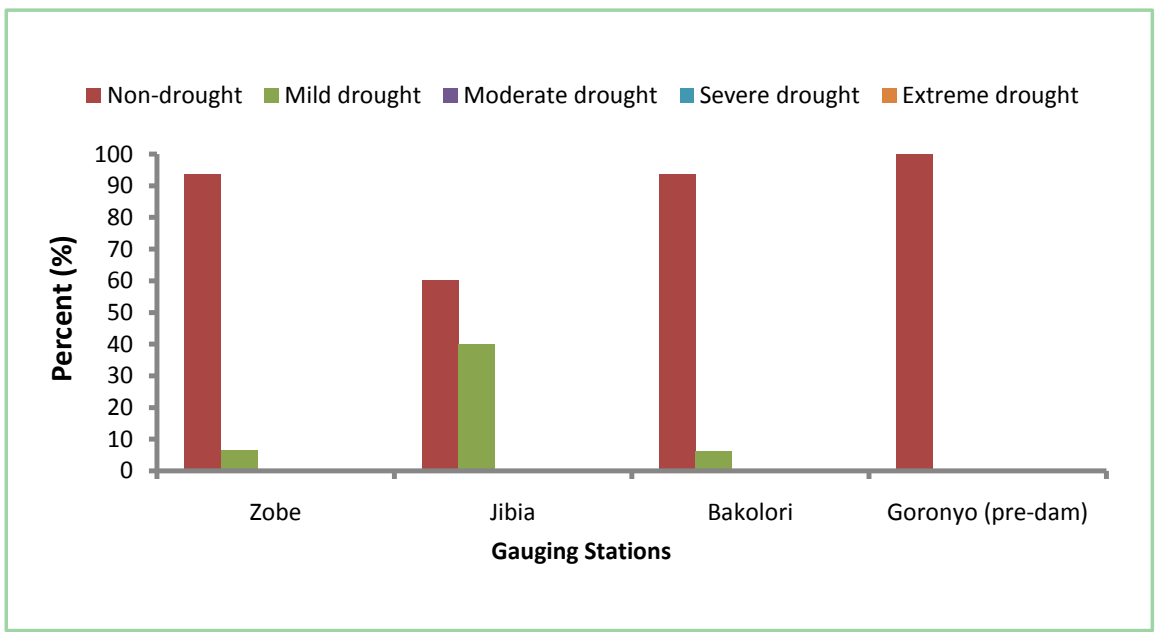

Figure 2. Frequency values of different drought conditions. 
Table 2. Computed average SDI values for long-term accumulation period.

\begin{tabular}{|c|c|c|c|c|}
\hline Stations & SDI & Class & $\begin{array}{c}\text { Computed Average } \\
\text { SDI }(\mathrm{K}=4)\end{array}$ & Probability (\%) \\
\hline \multicolumn{5}{|l|}{ Zobe } \\
\hline & $\geq 0.0$ & Non-drought & 0.5 & 93.50 \\
\hline & $-1.0 \leq \mathrm{SDI}<0.0$ & Mild drought & 0.35 & 6.45 \\
\hline & $-1.5 \leq \mathrm{SDI}<-1.0$ & Moderate drought & 0 & 0.00 \\
\hline & $-2.0 \leq \mathrm{SDI}<-1.5$ & Severe drought & 0 & 0.00 \\
\hline & $\mathrm{SDI}<-2.0$ & Extreme drought & 0 & 0.00 \\
\hline \multicolumn{5}{|l|}{ Goronyo 1} \\
\hline & $\geq 0.0$ & Non-drought & 0.67 & 100 \\
\hline & $-1.0 \leq \mathrm{SDI}<0.0$ & Mild drought & 0.00 & 0.00 \\
\hline & $-1.5 \leq \mathrm{SDI}<-1.0$ & Moderate drought & 0.00 & 0.00 \\
\hline & $-2.0 \leq \mathrm{SDI}<-1.5$ & Severe drought & 0.00 & 0.00 \\
\hline & $\mathrm{SDI}<-2.0$ & Extreme drought & 0.00 & 0.00 \\
\hline \multicolumn{5}{|l|}{ Goronyo 2} \\
\hline & $\geq 0.0$ & Non-drought & 0.43 & 100 \\
\hline & $-1.0 \leq \mathrm{SDI}<0.0$ & Mild drought & 0.00 & 0.00 \\
\hline & $-1.5 \leq \mathrm{SDI}<-1.0$ & Moderate drought & 0.00 & 0.00 \\
\hline & $-2.0 \leq \mathrm{SDI}<-1.5$ & Severe drought & 0.00 & 0.00 \\
\hline & $\mathrm{SDI}<-2.0$ & Extreme drought & 0.00 & 0.00 \\
\hline \multicolumn{5}{|l|}{ Gusau } \\
\hline & $\geq 0.0$ & Non-drought & 1.35 & 100 \\
\hline & $-1.0 \leq \mathrm{SDI}<0.0$ & Mild drought & 0.00 & 0.00 \\
\hline & $-1.5 \leq \mathrm{SDI}<-1.0$ & Moderate drought & 0.00 & 0.00 \\
\hline & $-2.0 \leq \mathrm{SDI}<-1.5$ & Severe drought & 0.00 & 0.00 \\
\hline & $\mathrm{SDI}<-2.0$ & Extreme drought & 0.00 & 0.00 \\
\hline \multicolumn{5}{|l|}{ Jibia } \\
\hline & $\geq 0.0$ & Non-drought & 0.30 & 60.00 \\
\hline & $-1.0 \leq \mathrm{SDI}<0.0$ & Mild drought & -0.18 & 40.00 \\
\hline & $-1.5 \leq \mathrm{SDI}<-1.0$ & Moderate drought & 0.00 & 0.00 \\
\hline & $-2.0 \leq \mathrm{SDI}<-1.5$ & Severe drought & 0.00 & 0.00 \\
\hline & $\mathrm{SDI}<-2.0$ & Extreme drought & 0.00 & 0.00 \\
\hline \multicolumn{5}{|l|}{ Bakolori } \\
\hline & $\geq 0.0$ & Non-drought & 0.0 .47 & 93.00 \\
\hline & $-1.0 \leq \mathrm{SDI}<0.0$ & Mild drought & $0 . .004$ & 6.25 \\
\hline & $-1.5 \leq \mathrm{SDI}<-1.0$ & Moderate drought & 0.00 & 0.00 \\
\hline & $-2.0 \leq \mathrm{SDI}<-1.5$ & Severe drought & 0.00 & 0.00 \\
\hline & $\mathrm{SDI}<-2.0$ & Extreme drought & 0.00 & 0.00 \\
\hline
\end{tabular}

Note: 1 = pre dam, 2 = post dam. 
Table 3. Frequency of state transition for the gauging stations.

(a)

\begin{tabular}{|c|c|c|c|c|c|c|c|c|c|}
\hline \multicolumn{5}{|c|}{ 1) Zobe } & \multicolumn{5}{|c|}{ 2) Jibia } \\
\hline \multirow{2}{*}{$\begin{array}{l}\text { State for } \\
\text { April-Sept }\end{array}$} & \multicolumn{4}{|c|}{ State for April-Dec } & \multirow{2}{*}{$\begin{array}{l}\text { State for } \\
\text { April-Sept }\end{array}$} & \multicolumn{4}{|c|}{ State for April-Dec } \\
\hline & 0 & 1 & 2 & 3 & & 0 & 1 & 2 & 3 \\
\hline 0 & 0.50 & 0.06 & 0.00 & 0.00 & 0 & 0.50 & 0.40 & 0.00 & 0.00 \\
\hline 1 & 0.90 & 0.50 & 0.00 & 0.00 & 1 & 0.60 & 0.50 & 0.00 & 0.00 \\
\hline 2 & 0.00 & 0.00 & 0.00 & 0.00 & 2 & 1.00 & 1.00 & 0.00 & 0.00 \\
\hline 3 & 0.00 & 0.00 & 0.00 & 0.00 & 3 & & & & \\
\hline \multirow{2}{*}{$\begin{array}{l}\text { State for } \\
\text { April-Dec }\end{array}$} & \multicolumn{4}{|c|}{ State for April-Mar } & State for & \multicolumn{4}{|c|}{ State for April-Mar } \\
\hline & 0 & 1 & 2 & 3 & April-Dec & 0 & 1 & 2 & 3 \\
\hline 0 & 0.50 & 0.06 & 0.00 & 0.00 & 0 & 0.50 & 0.40 & 0.00 & 0.00 \\
\hline 1 & 0.90 & 0.50 & 0.00 & 0.00 & 1 & 0.60 & 1.00 & 0.00 & 0.00 \\
\hline 2 & 1.00 & 1.00 & 0.00 & 0.00 & 2 & 1.00 & 1.00 & 0.00 & 0.00 \\
\hline 3 & 1.00 & 1.00 & 0.00 & 0.00 & 3 & 1.00 & 1.00 & 0.00 & 0.00 \\
\hline
\end{tabular}

(b)

\begin{tabular}{|c|c|c|c|c|c|c|c|c|c|}
\hline \multicolumn{5}{|c|}{ 1) Bakolori } & \multicolumn{5}{|c|}{ 2) Goronyo (pre-dam) } \\
\hline \multirow{2}{*}{$\begin{array}{l}\text { State for } \\
\text { April-Sept }\end{array}$} & \multicolumn{4}{|c|}{ State for April-Dec } & \multirow{2}{*}{$\begin{array}{c}\text { State for } \\
\text { April-Sept }\end{array}$} & \multicolumn{4}{|c|}{ State for April-Dec } \\
\hline & 0 & 1 & 2 & 3 & & 0 & 1 & 2 & 3 \\
\hline 0 & 0.48 & 0.06 & 0.00 & 0.00 & 0 & 0.50 & 0.00 & 0.00 & 0.00 \\
\hline 1 & 1.00 & 1.00 & 0.00 & 0.00 & 1 & 1.00 & 0.00 & 0.00 & 0.00 \\
\hline 2 & 1.00 & 1.00 & 0.00 & 0.00 & 2 & 1.00 & 0.00 & 0.00 & 0.00 \\
\hline 3 & 1.00 & 1.00 & 0.00 & 0.00 & 3 & 1.00 & 0.00 & 0.00 & 0.00 \\
\hline \multirow{2}{*}{$\begin{array}{l}\text { State for } \\
\text { April-Dec }\end{array}$} & \multicolumn{4}{|c|}{ State for April-Mar } & State for & \multicolumn{4}{|c|}{ State for April-Mar } \\
\hline & 0 & 1 & 2 & 3 & April-Dec & 0 & 1 & 2 & 3 \\
\hline 0 & 0.50 & 0.06 & 0.00 & 0.00 & 0 & 0.50 & 0.00 & 0.00 & 0.00 \\
\hline 1 & 0.94 & 0.50 & 0.00 & 0.00 & 1 & 1.00 & 0.00 & 0.00 & 0.00 \\
\hline 2 & 1.00 & 1.00 & 0.00 & 0.00 & 2 & 1.00 & 0.00 & 0.00 & 0.00 \\
\hline 3 & 1.00 & 1.00 & 0.00 & 0.00 & 3 & 1.00 & 0.00 & 0.00 & 0.00 \\
\hline
\end{tabular}

Based on the discourse, some pertinent concerns arise. Generally, it suffices to note that different indices have been employed in the characterisation of hydrological drought but many of the proposed indices do not enable a probabilistic assessment of the drought characteristics. In addition, each index describes a specific feature of drought. Thus in view of this, there is the need to merge the information from the host of indices employed into one value representative of the different features of the natural hydrological phenomenon; but this is a herculean task. Hence, efforts in this regard should ensure that routine characterisation and monitoring while taking into cognisance that drought conditions depicted by the indices not always reflect the actual risk of water shortage but be evaluated on the basis of the actual reliability of the water supply systems. 


\section{Implications and Strategy for Sustainable Water Resources Management}

From the available record at a particular site for a certain period, the trends in streamflow can be detected. Three devices used to study the variability of the flow that have direct applications in resource planning are frequency curve, mass curve, and duration curve. The primary objective of a flow duration curve is to ascertain how often flow of a given magnitude occurred during the period of record. In a statistical sense, a duration curve represents the cumulating of the frequency distribution curve; it can be of daily flows, mean monthly flows, or mean annual flows; thus employing either of these strategies provides an appraisal platform for flow value analysis at various dependability. In the light of this, Figure 3 and Figure 4 provide monthly flow duration curves (FDC) with associated least square regression models for the stations considered; i.e. Goronyo (pre and post dam situations), Jibia and Bakolori. The FDC's generally exhibits steep or sharp slopes with gentle but slow decaying long end-tail. The fast decaying sharp phase of the curve is indicative of the fact that in all these stations, the available stream channels dissipate water so quickly, that is, substantial volume of water upon release from the reservoir is lost via surface runoff for flood regulation. This could be due in part to high fluctuations in the annual flows of the River Rima. On the other hand, the slow decaying end-tail of the curves can be attributable to a flat and gentle topography of the area. Another attribute of the curves is upper bound. The models in all instances have high Coefficient of determination $\left(\mathrm{R}^{2}\right)$ values; though the prediction capability for purposes of evaluating exceedance probabilities of flow for the respective stations contrasts so much. This could be due to issues of data coherence or regularity especially where there are a lot of zero flow values. However, the $\mathrm{R}^{2}$ value as in Figure 3(a) and Figure 4(a) respectively accounts for about $73.3 \%$ and $86.5 \%$ variation in streamflow dynamics across the basin concomitant of changing climate effects.

As noted in the preceding section, Figure 5 and Figure 6 show the typology of rainfall and streamflow anomalies over the entire basin for the case under review. These periods under reckoning are quite extensive considering the overall effect. However, it is important to note that the simplicity of the rainfall anomaly concept greatly undermines its practical adoption in real-time. For instance, a drought initiation time is usually identified at the point when the cumulative anomaly begins a substantial decline which is determined subjectively. As noted here, in tandem with the findings of Keyantash and Dracup (2002), the instant at which a drought begins is of great importance but this approach does not capture it. On the other hand, the objective of the cumulative streamflow anomaly is to establish the cumulative departure of streamflow from mean conditions as it does show long-term tendencies in water availability. Thus, it suffices to note that the steep decline in the cumulative streamflow anomaly represents drought situations; especially as seen in Zobe and Jibia stations. 


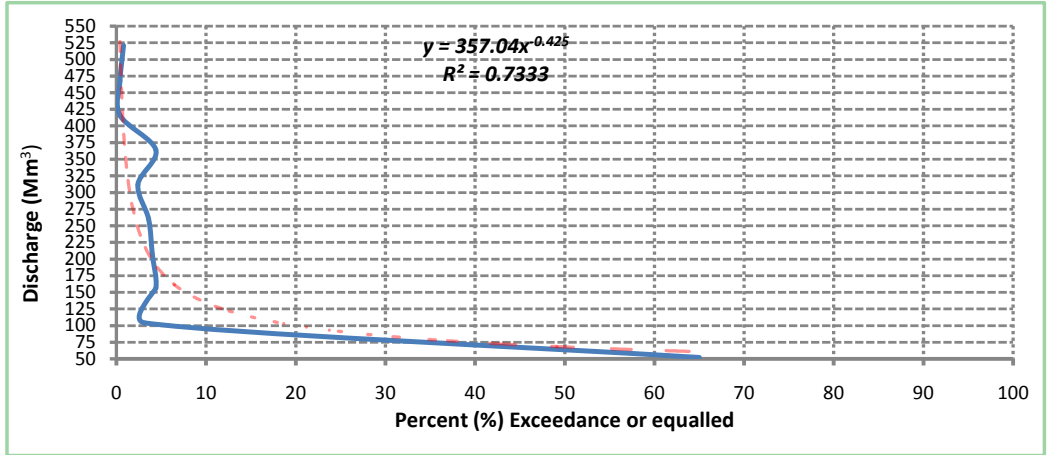

(a)

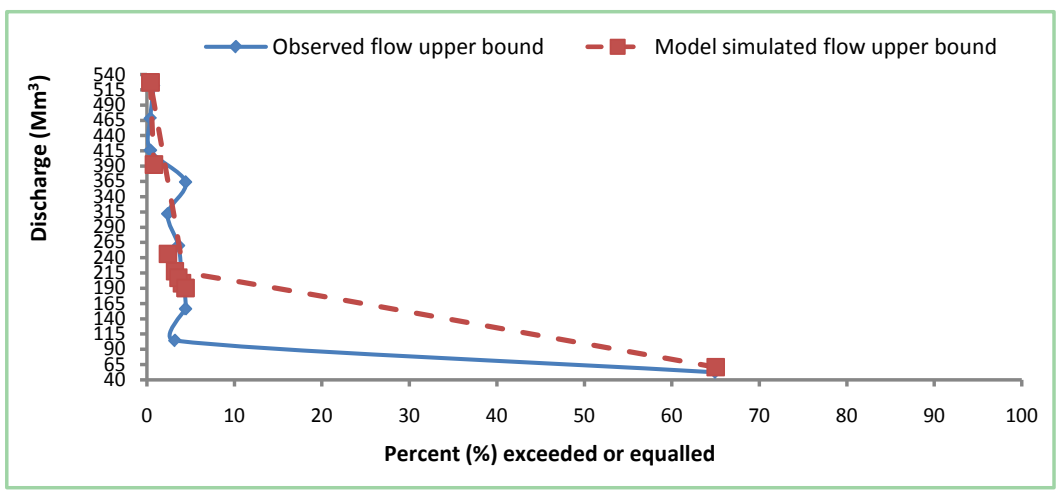

(b)

Figure 3. Monthly flow duration curves for Goronyo pre-dam situation considering (a) exceedance probabilities and (b) simulation of upper bounds. Note: Blue and red dotted lines, respectively depict observed streamflow and fitted trend model.

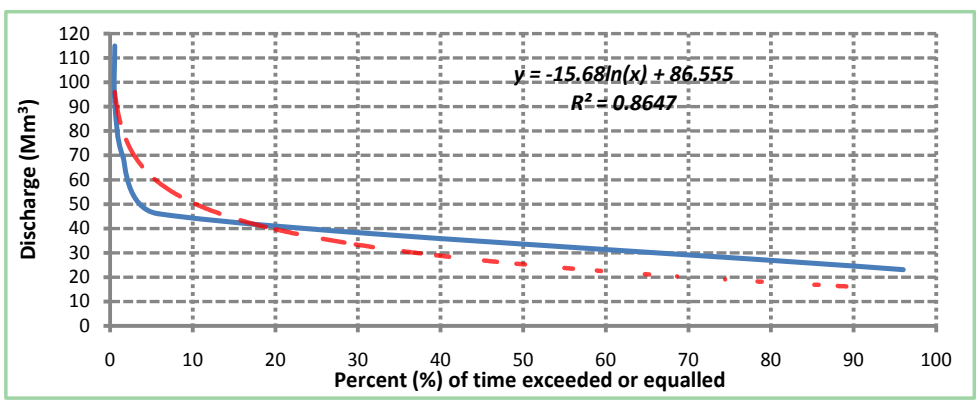

(a)

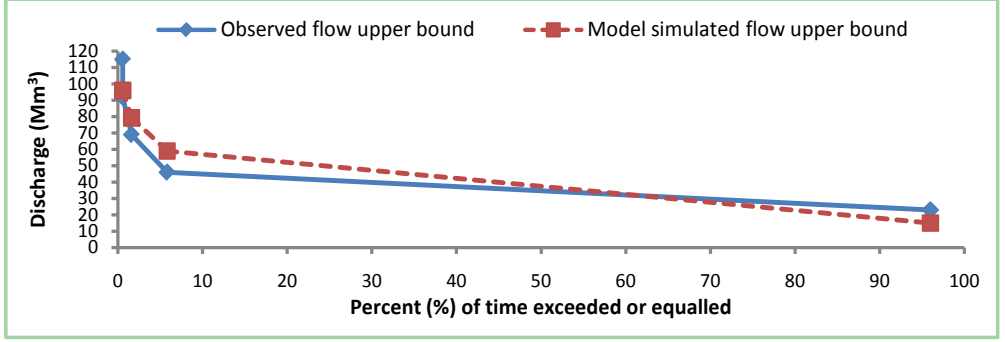

(b)

Figure 4. Flow duration curves of Goronyo (post dam construction) in months showing (a) exceedance probabilities and (b) simulation of flow regime upper bounds. 


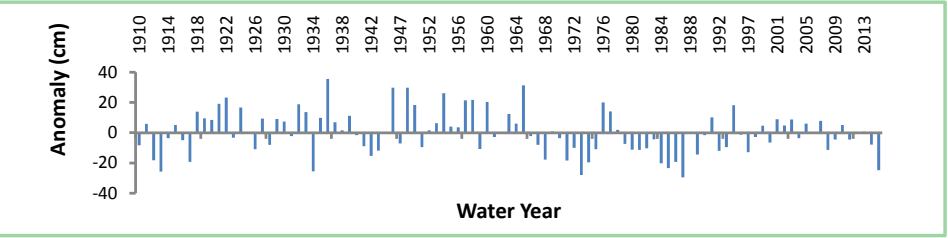

(a)

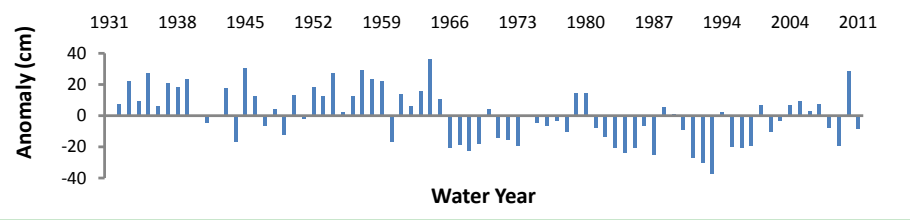

(b)

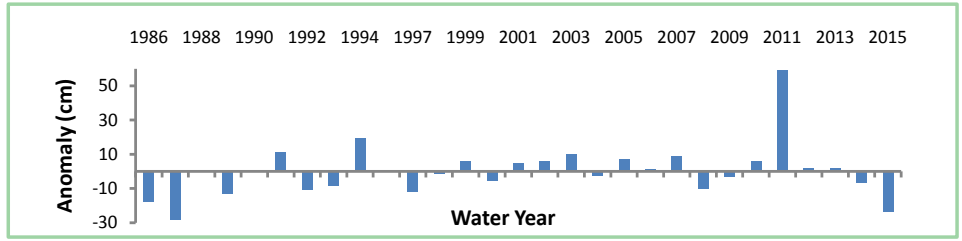

(c)

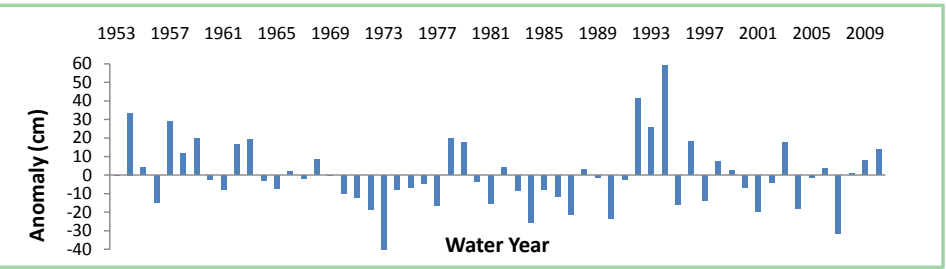

(d)

Figure 5. Annual rainfall anomalies for the respective sub-basins of (a) Sokoto, (b) Katsina, (c) Goronyo (post dam construction period), and (d) Gusau.

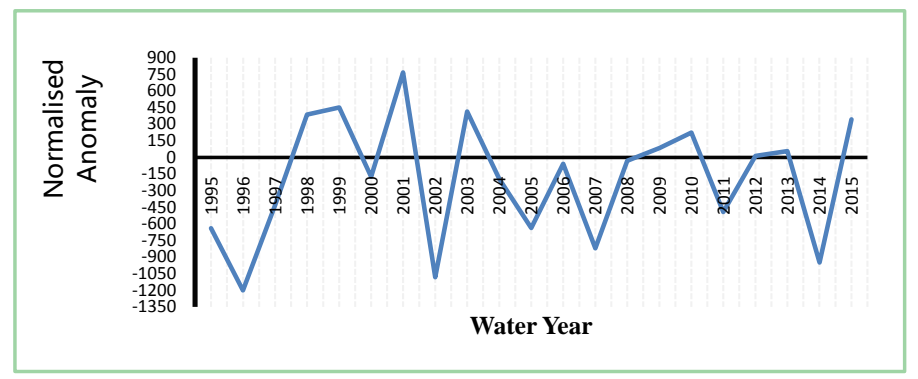

(a)

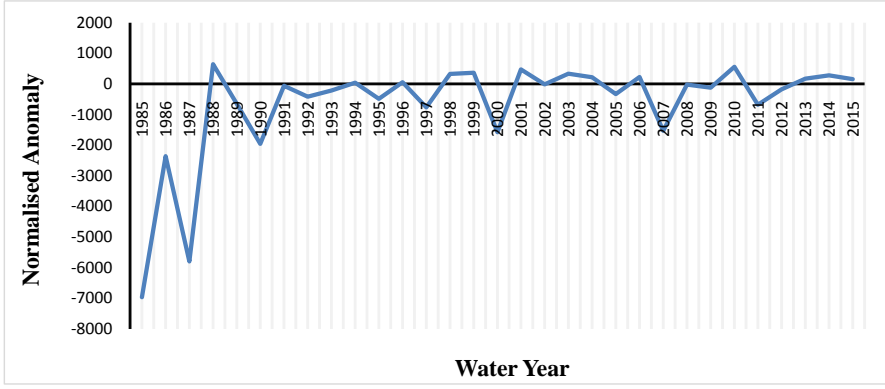

(b) 


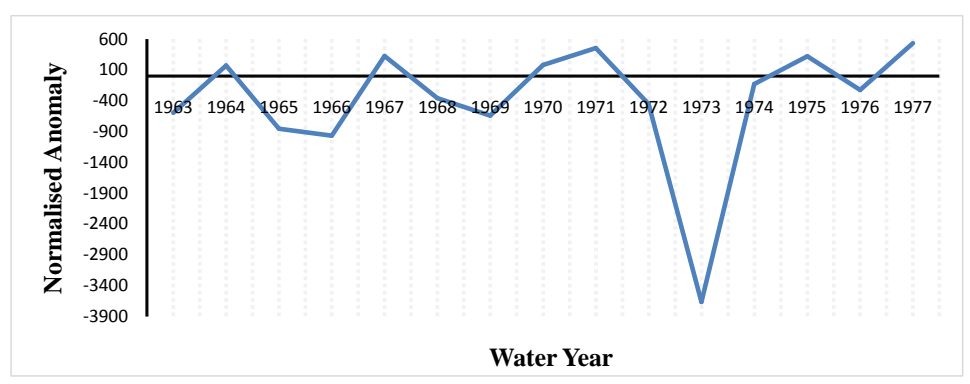

(c)

Figure 6. Normalised cumulative monthly streamflow anomaly expressed in thousandths of the annual streamflow for the respective sub-basins of (a) Goronyo (post dam construction), (b) Zobe, and (c) Jibia.

The physical implications of the findings generally hinge on the type of indices employed and absence or otherwise of robust criteria vis-à-vis robust policy framework for routine assessment. In this context, concern is more on how to deal with suitable choice of index to work with; it is difficult to deal with a variety of distinct characteristics and impacts of hydrological drought. For instance, duration of zero-flow periods, streams never fall dry and even failure of models to capture appropriately low flows sufficiently. For this particular case under discourse, there is implication for defined policy adoption; there is no seeming physical policy for adoption to recover from extreme drought event associated with lack of proper definition of territorial unit to be considered for different levels of planning and relevant institutional interventions. Against the backdrop of the concerns in the preceding section, for sustainability of long-term management design, recourse should be to ensuring that: 1) ecosystem based management as well as ecological restoration be considered, 2) routine characterisation of drought regime encompasses an evolution of the temporal and spatial distribution of drought within the basin as well as 3) designing policy to reflect the understanding that support is required along the value chain not just for production support but towards reducing the water dependence of added value.

\section{Conclusion}

Based on the method employed in evaluating the hydrological drought and its characterisation, all the stations: Bakolori, Goronyo, Jibia, Zobe, Katsina and Gusau, Bakolori experienced near normal drought classification conditions on the average though with minor traces of mild hydrologic drought conditions. The average deficit volume (severity of drought) and drought durations stood at $1.780 \mathrm{Mm}^{3}$ and 192 months, $1.444 \mathrm{Mm}^{3}$ and 252 months, $3.148 \mathrm{Mm}^{3}$ and 252 months, and $0.159 \mathrm{Mm}^{3}$ and 372 months for Bakolori, Goronyo (pre dam construction era), Goronyo (post dam construction era) and Zobe stations, respectively. In general, it suffices to note that the application of FDC is a veritable construct for flow analysis, especially for reservoir management in this regard. The developed regression models provide for multiple scenario basin water resources development and management frameworks as typified by the explana- 
tory power of the $\mathrm{R}^{2}$ along with the frequency of drought state transitions. Worthy of note is the adoption of other forms such as Variable Threshold methods and its primary form or its variants; this, sometimes might lead to overestimation of the number of drought events. However, the assessment of hydrological drought plays an essential role in sustainable water resources management considering the fact that recovery from it is usually prolonged in view of recovery time of river systems. Thus, it is apt to routinely evaluate the conditions of drought; in this regard, hydrological drought characterisation should encompass strategic, tactical and energy levels by detailing spatial components such as synchronicity, clustering and breaking up of clusters of droughts. In this regard too, it suffices to note that due to the fluctuations of the drought behavior as a result of natural climate variability, the drought characteristics derived from a streamflow record fluctuate from year to year. Thus, it is therefore imperative to analyse the persistence and recurrence in time. Similarly, since droughts are regional events, routine statistical analysis is needed to assess the variability within affected area and thus by extension determine the possible recurrent patterns.

\section{Conflicts of Interest}

The authors declare no conflicts of interest regarding the publication of this paper.

\section{References}

[1] Ali, Z., Hussain, I. and Faisal, M. (2019) Annual Characterisation of Regional Hydrological Drought Using Auxiliary Information under Global Warming Scenario. Natural Hazards and Earth System Sciences, 1-20. https://doi.org/10.5194/nhess-2018-373

[2] Van Loon, A.F. and Laaha, G. (2015) Hydrological Drought Severity Explained by Climate and Catchment Characteristics. Journal of Hydrology, 526, 3-14. https://doi.org/10.1016/j.jhydrol.2014.10.059

[3] Nalbantis, I. (2008) Evaluation of a Hydrological Drought Index. European Water, 23/24, 67-77.

[4] Van Loon, A.F. (2015) Hydrological Drought Explained. Wiley Interdisciplinary Reviews, 2, 359-392. https://doi.org/10.1002/wat2.1085

[5] Mishra, K. and Singh, VP. (2010) A Review of Draft Concepts. Journal of Hydrolo$g y$, 391, 202-216. https://doi.org/10.1016/j.jhydrol.2010.07.012

[6] Pozzi, W., Sheffield, J., Stefanski, R., Cripe, D., Pulwarty, R., Vogt, J.V., Heim, R.R., Brewer, M.J., Svoboda, M. and Westerhoff, R. (2013) Towards Global Drought Early Warning Capability: Expanding International Cooperation the Development of a Framework for Monitoring and Forecasting. Bulletin of the American Meteorological Society, 94, 776-785. https://doi.org/10.1175/BAMS-D-11-00176

[7] Sceneviratne, S.I., Easter ling, D., Goodess, C.M., Kanea, S., Kossim, J., Luo, Y., Marengo, J., Mclnnes, K. and Rahimi, M. (2012) Changes in Climate Extremes and Their Impacts on the Natural Physical Environment. A Special Report of Working Groups 1 and II of the Intergovernmental Panel on Climate Change (IPCC), Cambridge University Press Cambridge, UK.

https://doi.org/10.1017/CBO9781139177245.006 
[8] Huijgevoort, V.J.M.H., Hazenberg, P., Van Lanen, H.A.J. and Uijlenhoet, R. (2012) A Generic Method for Hydrologic Drought Identification across Different Climate Regions. Hydrology and Earth System Sciences, 16, 2437-2451. https://doi.org/10.5194/hess-16-2437-2012

[9] Danmagaji, A. (2017) Determination of Potential Hydrological Drought in the Sokoto-Rima River Basin, Nigeria. M.Eng Thesis, Federal University of Technology, Minna.

[10] Sardou, F.S. and Bahremand, A. (2014) Hydrological Drought Analysis Using SDI index in Hilarud Basin of Iran. Environmental Resources Research, 2, 48-56.

[11] Keyantash, J. and Dracup, J.A. (2002) The Quantification of Drought: An Evaluation of Drought Indices. American Meteorological Society, BAMS, 1167-1180. https://doi.org/10.1175/1520-0477-83.8.1167 